\title{
ACTN3 R577X Polymorphism Impacts Glucose Consumption at Simulated High Altitude
}

\author{
Ricardo Muller Bottura ${ }^{1,}$, Giscard Humberto Oliveira Lima ${ }^{2,3}$, Debora Cristina Hipolide ${ }^{1}$, \\ Joao Bosco Pesquero ${ }^{3}$
}

${ }^{1}$ Psychobiology Department, Federal University of Sao Paulo (UNIFESP), Sao Paulo, Brazil

${ }^{2}$ Department of Movement, Human and Health Sciences, University of Rome "Foro Italico", Rome, Italia

${ }^{3}$ Biophysics Department, Federal University of Sao Paulo (UNIFESP), Sao Paulo, Brazil

\section{Email address:}

rbottura@hotmail.com (R. M. Bottura),giscard.lima@gmail.com (G. H. O. Lima), debora.hipolide@gmail.com (D. C. Hipolide), jbpesquero@unifesp.br(J.B. Pesquero)

${ }^{*}$ Corresponding author

\section{To cite this article:}

Ricardo Muller Bottura, Giscard Humberto Oliveira Lima, Debora Cristina Hipolide, Joao Bosco Pesquero. ACTN3 R577X Polymorphism Impacts Glucose Consumption at Simulated High Altitude. International Journal of Genetics and Genomics.

Vol. 8, No. 4, 2020, pp. 138-142. doi: 10.11648/j.ijgg.20200804.14

Received: October 26, 2020; Accepted: November 10, 2020; Published: November 23, 2020

\begin{abstract}
Introduction: High altitude acclimatization is a process that involve several physiological adjustments, which may increase glucose metabolism because of acute hypoxic exposure. Native highlanders like Tibetans show an increased anaerobic glucose metabolism and a higher proportion of type I muscle fiber than lowlanders. Actin filaments are anchored to the $\mathrm{Z}$ line of the sarcomere by a protein called alpha-actinin that exist in two isoforms in the muscle (ACTN2 and ACTN3), however $A C T N 3$ is present only in type II fibers, especially in type IIx. Homozygous individuals for a 577X polymorphism in the $A C T N 3$ gene do not express $A C T N 3$ and seem to be more type I muscle fiber than homozygous individuals 577R. The aim of this study was to compare the glucose consumption response of individuals with different $A C T N 3$ genotypes at simulated 4,500 $\mathrm{m}$ altitude. Materials \& Methods: Twenty-three volunteers spent four hours exposed to a simulated altitude of 4,500 $\mathrm{m}$ inside a normobaric hypoxia chamber. Lactate and glucose concentrations, $\mathrm{SpO}_{2}$ and heart rate were analyzed immediately before entering the chamber and at each hour during the exposure. Results: Glucose after four hours of exposure to hypoxia was different between groups, with RX $(68.1 \pm 11.7 \mathrm{mg} / \mathrm{dl})$ and RR $(71.7 \pm 14.4 \mathrm{mg} / \mathrm{dl})$ showing a decreased blood glucose compared to XX $(88.7 \pm 14.1 \mathrm{mg} / \mathrm{dl})$, indicating an increased dependence on glucose metabolism in individuals with at least one $\mathrm{R}$ allele after exposure at 4,500 $\mathrm{m}$ simulated altitude. Conclusions: We concluded that individuals with at least one $\mathrm{R}$ allele of the ACTN3 R577X gene polymorphism consume more glucose than the ones with XX genotype.
\end{abstract}

Keywords: $A C T N 3$, Glycemia, Hypoxia, Hypoxemia, Muscle Fiber Type

\section{Introduction}

High altitude acclimatization is a process that involves several physiological adjustments like increasing heart rate, ventilation [18] and glucose consumption [12]. Although there is some evidence of a hyperglycemia within short-term exposure to high altitude [17], literature also shows an enhanced glucose metabolism because of acute hypoxic exposure [16]. Considering the role of genetic factors to a better acclimatization, high altitude native population may be a primary source for studies on this topic. High altitude adapted Tibetans show an increased anaerobic glucose metabolism and a decreased fatty acid oxidation [10], while Sherpas have a genetic selection (advantageous PPARA alleles in two of three SNPs) that allow them to improve muscle energetics [13]. In addition, Sherpas and Tibetans have a higher proportion of type I muscle fiber than lowlanders [11], which suggest another physiologic advantage. There are basically two types of skeletal muscle fiber (I and II), and among the structural differences between 
them, the $\alpha$-actinin 3 is a protein that is expressed only in fiber type II (whereas $\alpha$-actinin 2 protein is expressed in fiber types I and II). However, a polymorphism in the $\alpha$-actinin3 gene (ACTN3, rs 1815729) leads to an exchange of an arginine for a stop codon at position 577 of the protein, generating three different genotypes (XX, RX and RR). Individuals carrying the variant $\mathrm{R} 577 \mathrm{X}$ in homozygous (individuals $\mathrm{XX}$ ) do not express the protein ACTN3 [20] and possess more type I muscle fiber than homozygous individuals for the allele $\mathrm{R}$ [25]. Our hypothesis is that the presence of higher amount of type I fiber in homozygous individuals for the variant $\mathrm{X}$ provide faster acclimatization after exposure at higher altitudes. Therefore, the aim of this study was to compare the glucose consumption response of individuals with different $A C T N 3$ genotypes at simulated altitude of $4,500 \mathrm{~m}$.

\section{Materials and Methods}

\subsection{Participants}

Epithelial cells from the buccal mucosa of 61 volunteers ( 39 men and 22 women) were collected for the evaluation of the ACTN3 R577X polymorphism, being $21 \mathrm{RR}, 32 \mathrm{RX}$ and $8 \mathrm{XX}$. Volunteers were classified as physically active by the International Physical Activity Questionnaire (IPAQ), without history of cardiovascular diseases and age ranging from 17 to 45 years old. Volunteers who were exposed to altitudes above $2,500 \mathrm{~m}$ up to six months prior to the experiment were excluded from the study. Experimental protocol was performed with 23 volunteers $(\mathrm{RR}=7, \mathrm{RX}=8$ and $\mathrm{XX}=8$ ). The study protocol was approved by the ethics committee of the Universidade Federal de São Paulo, Brazil (protocol number 2.001.055) and each subject provided informed written consent before participation. The sampling methodology has been defined previously [4].

\subsection{Experimental Design}

Volunteers were evaluated immediately before entering the chamber and one, two, three and four hours of exposure to hypoxia inside the normobaric chamber simulating $4,500 \mathrm{~m}$ of altitude. At each time point, blood samples were collected for the evaluation of plasma lactate and glucose concentrations. Heart rate (HR) and peripheral oxygen saturation $\left(\mathrm{SpO}_{2}\right)$ were also measured at each moment. Volunteers were asked to keep fasting from the moment they woke up until the beginning of the experiment when they received a standard snack after the first analysis still outside the chamber. All experiments were conducted around $7 \mathrm{am}$.

\subsection{DNA Extration, Quantification and Genotyping}

Epithelial cells from the buccal mucosa were collected for genotyping by rubbing a swab on the inside of the cheek for approximately 30 seconds and samples were stored at low temperature $\left(4^{\circ} \mathrm{C}\right)$ until analysis. Chelex 100 was used to extract genomic DNA from the epithelial cells. Quantification was performed in a NanoDrop ${ }^{\circledR}-N D 1000$ spectrophotometer which evaluates the amount and quality of
DNA [9]. The SNP (single nucleotide polymorphism) analysis of the ACTN3 gene (rs1815729) was performed by a quantitative PCR using TaqMan ${ }^{\circledR}$ SNP genotyping assays (Applied Biosystems, Foster City, CA) and QuantStudio 5 (Applied Biosystems ${ }^{\circledR}$ ) (Schadock et al., 2015).

\subsection{Normobaric Altitude Chamber}

The Altitude Simulator (CAT - Colorado Altitude Training TM / 12 CAT-Air Unit) has four air units installed outside the chamber increasing nitrogen and reducing $\mathrm{O}_{2}$, which generates difference in the $\mathrm{O}_{2}$ concentration inside the chamber. A module containing a sensitive $\mathrm{O}_{2}$ cell, which displays the simulated altitude in real time, measures this difference.

\subsection{Physiological Variables}

A Fingerpulse $\AA$ finger oximeter, model MD300C202 was used to monitor $\mathrm{SpO}_{2}$ and $\mathrm{HR}$. Glucose and lactate were quantified through reflectance photometry through ROCHE's Accutrend Plus Monitor [3]. At each time point, a blood sample was collected from the tips of the fingers after they have been sanitized with BIOSOMA alcohol swab and drilled with a BIOLAND Model SB-323 auto lancet.

\subsection{Statistics Analysis}

Shapiro-Wilk normality test was used and since all variables were normal, data were presented in mean and standard deviation. Multivariate General Linear Models (GLM) with Bonferroni post-hoc were used for the analyses among groups (ACTN3) and time (hours of exposure). The level of significance was $\alpha \leq 5 \%$. To perform the tests, the IBM SPSS Statistics 21 software was used.

\section{Results}

Table 1 shows the descriptive characteristics of the sample in relation to the anthropometric variables classified by the genotypes of $A C T N 3 R 577 X$. Comparisons between groups did not show significant differences for any of the variables. One volunteer homozygous for the allele $\mathrm{R}$ was excluded from the study because of baseline glycemia of $162 \mathrm{mg} / \mathrm{dl}$, which is well above normal $(<125 \mathrm{mg} / \mathrm{dl})$. It was also excluded, before statistics analysis, an outlier lactate value from the analysis (one hour) of a volunteer (RR) who presented with $19.1 \mathrm{mmol} / \mathrm{l}$, a value well above normal for the sample $(2.59 \pm 0.96 \mathrm{mmol} / \mathrm{l})$.

Table 1. Descriptive characteristics of volunteers classified by genotype.

\begin{tabular}{llllll}
\hline & XX & RX & RR & $\boldsymbol{F}$ & $\boldsymbol{P}$ \\
\hline Age (years) & $27.0(7.3)$ & $32.8(9.1)$ & $26.4(7.2)$ & 1.54 & 0.23 \\
Weight $(\mathrm{kg})$ & $69.1(7.5)$ & $72.1(22.7)$ & $69.2(11.8)$ & 0.09 & 0.91 \\
Height $(\mathrm{m})$ & $1.70(0.05)$ & $1.66(0.14)$ & $1.67(0.06)$ & 0.30 & 0.74 \\
BMI $\left(\mathrm{kg} / \mathrm{m}^{2}\right)$ & $23.9(2.4)$ & $25.5(4.4)$ & $24.4(3.2)$ & 0.44 & 0.64 \\
\hline
\end{tabular}

Note: Values described as mean (SD). XX, RX and RR are the genotypes of ACTN3. $\mathrm{XX}(\mathrm{N}=8), \mathrm{RX}(\mathrm{N}=8), \mathrm{RR}(\mathrm{N}=7)$. $\mathrm{BMI}=$ Body Mass Index. Values of the variables age, weight, height and BMI are described as mean \pm standard deviation. $\mathrm{F}$ is the value of the GLM analysis. It was considered $\mathrm{p}$ $<0.05$. 
The comparative values of the physiological variables over time are described in Table 2. Among the physiological parameters analyzed, glucose after four hours of exposure to hypoxia $[\mathrm{F}(8,400)=2.003, \mathrm{p}<0.05]$ demonstrated a difference between groups. The RX $(68.1 \pm 11.7 \mathrm{mg} / \mathrm{dl}, 88.7$ $\pm 14.1 \mathrm{mg} / \mathrm{dl}, \mathrm{F}(-3.068), \mathrm{p}<0.01)$ and RR genotypes $(71.7 \pm$ $14.4 \mathrm{mg} / \mathrm{dl}, 88.7 \pm 14.1 \mathrm{mg} / \mathrm{dl}, \mathrm{F}(-2.448), \mathrm{p}<0.05)$ showed a decreased blood glucose compared to XX. In addition, RX genotype showed a difference between one hour $(\mathrm{p}<0.05)$ and two hours $(\mathrm{p}<0.01)$ when compared to four hours. The values of all physiological measures by group and time are presented in Table 3. The variables $\mathrm{SpO}_{2}[\mathrm{~F}(4,427.3)=36.4$, $\mathrm{p}<0.01]$ and $\operatorname{HR}[\mathrm{F}(2,2.363 .2)=4.896, \mathrm{p}<0.01]$ showed differences over time. $\mathrm{SpO}_{2}$ before entering the chamber was higher than all time in hypoxia $(\mathrm{p}<0.01)$ while the moment before entering the chamber showed lower HR values than three $(\mathrm{p}<0.05)$ and four hours $(\mathrm{p}<0.01)$ of altitude exposure.

Table 2. GLM analysis of the physiological variables over the 4 hours exposure to the simulated altitude of 4,500 $\mathrm{m}$.

\begin{tabular}{|c|c|c|c|c|c|}
\hline & Before & $1 \mathrm{~h}$ & $2 \mathrm{~h}$ & $3 \mathbf{h}$ & $4 \mathrm{~h}$ \\
\hline HR (bpm) & $73.2(12.5)$ & $78.3(9.1)$ & $76.9(10.5)$ & $79.2(9.9)^{\mathrm{a}}$ & $80.8(13.6)^{\mathrm{a}}$ \\
\hline Glucose (mg/dl) & $82.0(1.6)$ & $91.4(3.0)$ & $84.5(3.5)$ & $78.5(2.2)$ & $76.3(10.9)$ \\
\hline $\mathrm{SpO}_{2}(\%)$ & $96.2(0.9)$ & $85.8(0.9)^{\mathrm{a}}$ & $85.8(1.4)^{\mathrm{a}}$ & $88.3(0.4)^{\mathrm{a}}$ & $88.8(1.2)^{\mathrm{a}}$ \\
\hline Lake Louise (score) & $0.4(0.2)$ & $0.4(0.2)$ & $0.4(0.4)$ & $0.6(0.4)$ & $0.9(0.5)$ \\
\hline
\end{tabular}

Note: $\mathrm{HR}=$ Heart Rate, $\mathrm{SpO} 2=$ Peripheral Oxygen Saturation, $\mathrm{mg} / \mathrm{dL}=$ milligrams per deciliter, mmol/L=millimoles per liter, bpm=beats per minute, $\mathrm{mmHg}=$ millimeters of mercury. Values described as mean (SD) $(\mathrm{n}=115)$. ${ }^{\mathrm{a}}$ Difference when compared to time BEFORE (HR Three Hours, $\mathrm{p}<0.05 / \mathrm{HR}$ Four Hours, $\mathrm{p}<0.01 / \mathrm{SpO} 2$ at ALL times, $\mathrm{p}<0.01$ ). It was considered $\mathrm{p}<0.05$.

Table 3. GLM analysis for the physiological variables associated with ACTN3 genotypes over the 4 hours exposure to the simulated altitude of 4,500 m.

\begin{tabular}{|c|c|c|c|c|c|c|c|c|c|}
\hline & \multicolumn{3}{|l|}{ Before } & \multicolumn{3}{|l|}{$1 \mathrm{~h}$} & \multicolumn{3}{|l|}{$2 \mathrm{~h}$} \\
\hline & $\mathbf{X X}$ & $\mathbf{R X}$ & $\mathbf{R R}$ & $\mathbf{X X}$ & $\mathbf{R X}$ & $\mathbf{R R}$ & $\mathbf{X X}$ & $\mathbf{R X}$ & $\mathbf{R R}$ \\
\hline Glucose (mg/dl) & $80.1(10.8)$ & $82.8(18.6)$ & $71.8(7.5)$ & $93.5(16.4)$ & $92.8(19.7)$ & $76.1(19.2)$ & $80.5(8.2)$ & $85.6(14.4)$ & $86.2(146)$ \\
\hline Lactate $(\mathrm{mmol} / \mathrm{l})$ & $2.0(1.5)$ & $2.0(1.0)$ & $1.4(0.8)$ & $2.7(1.0)$ & $2.6(0.9)$ & $2.5(0.7)$ & $2.4(1.0)$ & $2.2(0.6)$ & $1.8(0.6)$ \\
\hline HR (bpm) & $75.7(13.6)$ & $72.8(10.3)$ & $71.1(14.6)$ & $79.6(10.2)$ & $78.7(6.9)$ & $76.7(10.6)$ & 81.7 (11.4) & $75.1(10.1)$ & $74.0(9.5)$ \\
\hline $\mathrm{SpO}_{2}(\%)$ & $95.8(2.6)$ & $95.6(1.3)$ & $97.5(0.5)$ & $85.3(4.1)$ & $87.0(5.4)$ & $85.7(2.4)$ & $87.2(2.6)$ & $84.3(6.1)$ & $85.2(2.9)$ \\
\hline $\begin{array}{l}\text { Lake Louise } \\
\text { (positive score) }\end{array}$ & - & - & - & 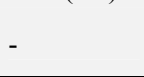 & - & 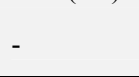 & - & - & 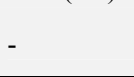 \\
\hline
\end{tabular}

Table 3. Continued.

\begin{tabular}{|c|c|c|c|c|c|c|}
\hline & \multicolumn{3}{|l|}{$3 \mathbf{h}$} & \multicolumn{3}{|l|}{$4 \mathrm{~h}$} \\
\hline & $\mathbf{X X}$ & $\mathbf{R X}$ & RR & $\mathbf{X X}$ & $\mathbf{R X}$ & RR \\
\hline Glucose (mg/dl) & $76.1(12.4)$ & $80.5(23.1)$ & $79.8(9.0)$ & $88.7(14.1)$ & $68.1(11.7)^{\mathrm{ab}}$ & $71.7(14.4)^{\mathrm{a}}$ \\
\hline Lactate (mmol/1) & $2.7(0.9)$ & $2.4(1.0)$ & $1.9(1.0)$ & $2.4(0.7)$ & $2.3(1.3)$ & $1.7(0.7)$ \\
\hline HR (bpm) & $81.8(10.3)$ & $80.6(10.1)$ & $75.1(9.0)$ & $85.0(14.7)^{\mathrm{c}}$ & $82.7(12.9)^{\mathrm{c}}$ & $74.7(12.5)$ \\
\hline $\mathrm{SpO}_{2}(\%)$ & $88.2(4.1)$ & $88.7(3.0)$ & $88.1(5.3)$ & $89.0(3.5)$ & $87.5(2.5)$ & $90.4(4.9)$ \\
\hline
\end{tabular}

Note: XX, RX and RR are the genotypes of ACTN3. $(\mathrm{N}=8), \mathrm{RX}(\mathrm{N}=8), \mathrm{RR}(\mathrm{N}=7), \mathrm{HR}=$ Heart Rate, SpO2=Peripheral Oxygen Saturation, mg/dl=milligrams per deciliter, $\mathrm{mmol} / \mathrm{l}=$ millimoles per liter, $\mathrm{bpm}=$ beats per minute, $\mathrm{mmHg}=$ millimeters of mercury. The values are described as Mean (SD) except Lake Louise, which shows how many individuals were diagnosed positive by time. adifference between RR ( $<<0.05)$ and RX ( $p<0.01)$ compared to XX in time 4 Hours; ${ }^{\mathrm{b}}$ difference in relation to the times $1 \mathrm{~h}(\mathrm{p}<0.05)$ and $2 \mathrm{~h}(\mathrm{p}<0.01)$; ${ }^{\mathrm{c}}$ difference in relation to time before.

\section{Discussion}

Literature shows that exposure to altitude increase glucose metabolism [5, 7], as well as the practice of physical activity and that these two factors could induce acute mountain sickness (AMS) symptoms $[19,22]$. Based on this, the volunteers of the present study received a standard snack immediately before entering the normobaric chamber to normalize blood glucose and did not perform any physical activity. Though there was not a significant difference, RR group showed a lower mean value of fasting glycemia. In 1976, Conlee et al. demonstrated that fasting alters glycogen content substantially and this slight difference in RR group may be due a higher glycogen phosphorylase activity compared to XX group [21]. Another recent study confirms that assumption by showing that $A C T N 3$ $577 \mathrm{XX} \mathrm{HIV}+$ patients have higher glycemia when compared to 577RR [2].

Our study revealed a higher glycemia after four hours exposure to high simulated altitude for XX group compared to RX and RR groups. Previous studies demonstrated that during exposure to altitude, glucose dependence increase as an energy substrate, since the lower $\mathrm{SaO}_{2}$ increase the metabolic dependence of glucose $[5,6]$. However, XX group 
was able to maintain the glycemia stable even after four hours of exposure compared with the RX and RR genotypes. A possible explanation is that individuals with $\mathrm{XX}$ genotype and possibly more type I muscle fibers are favored by the higher mitochondrial density in these fibers, compared to type IIx, allowing a higher supply of energy even with glucose as a primary source. This may be explained by the fact that XX individuals have less glycogen phosphorylase activity [21] and therefore may save glycogen throughout acute exposure to hypoxia, which reinforce our hypothesis that XX genotype may have a faster acclimatization in situations of extreme altitude.

However, group XX not only maintained but increased blood glucose between three and four hours of exposure to altitude. A second possibility refers to the fact that XX individuals have lower levels of cortisol at rest than individuals with at least one R allele [1]. Likewise, a study by Woods et al. [26] shows that acute exposure to high altitude raises cortisol levels. In addition to the fact that XX individuals have less activity of glycogen phosphorylase, this lower level of cortisol may have delayed the process of gluconeogenesis [15] compared to the groups $\mathrm{RX}$ and $\mathrm{RR}$, causing an increase in blood glucose after three hours in the XX group. Altogether, it would be of interest to examine the interaction of ACTN3 R577X polymorphism combined to stress hormone at simulated high altitude.

\section{Conclusion}

We conclude that there is a higher dependence of glucose as energetic substrate in individuals with at least one $\mathrm{R}$ allele of the ACTN3 R577X gene polymorphism which could be linked to metabolic differences that may favor energy substrates utilization at high altitude in $\mathrm{XX}$ genotype individuals.

\section{Limitations of the Study}

Because it is a study performed in a normobaric chamber, adverse situations such as cold, wind and physical activity involved in the process of climbing at high altitudes are not present, so the effects demonstrated here may have been suppressed. We suggest that new studies should be performed in hypobaric hypoxia to confirm the findings of this study.

\section{Authorship Confirmation Statement}

The main author was responsible for running all experiments under supervision of the coauthors. GHOL carried out the genotyping analysis. This research is part of the master's degree certification of the main author. All coauthors have reviewed and approved this manuscript before its submission.

\section{Acknowledgements}

The authors declare that they have no competing interests.

\section{References}

[1] Antonio J, Knafo S, Ellerbroek A, Vargas L, Silver T, Peacock C, Tartar J (2017). The Relationship between the ACTN3 Genotype and Measures of Stress, Exercise Performance and Body Composition: A Pilot Trial. Journal of Exercise. Dec; 20 (6): 139-53.

[2] Aranalde LC, Pederzoli BS, Marten T, Barros FC, Basso RP, Silveira JM, Valle SC, Pieniz S, Araujo RC, Paredes-Gamero EJ, Schadock I, Schneider A, Barros CC (2016). The ACTN3 R577X polymorphism affects the lipid profile and the prognosis of nutritional intervention in HIV-positive patients. Nutr Res. Jun; 36 (6): 564-74.

[3] Baldari C, Bonavolontà V, Emerenziani GP, Gallotta MC, Silva AJ, and Guidetti L (2009). Accuracy, reliability, linearity of Accutrend and Lactate Pro versus EBIO plus analyzer. Eur J Appl Physiol. 107 (1): 105-111.

[4] Bottura RM, Lima GHO, Hipolide DC, Pesquero JB (2019). Association between $A C T N 3$ and acute mountain sickness. Genes Environ. Dec 10; 41: 18.

[5] Brooks GA, Butterfield GE, Wolfe RR, Groves BM, Mazzeo RS, Sutton JR, Wolfel EE, and Reeves JT (1991). Increased dependence on blood glucose after acclimatization to $4,300 \mathrm{~m}$. J Appl Physiol. 70 (2): 919-927.

[6] Brooks GA, Wolfel EE, Groves BM, Bender PR, Butterfield GE, Cymerman A, Mazzeo RS, Sutton JR, Wolfe RR, and Reeves JT (1992). Muscle accounts for glucose disposal but not blood lactate appearance during exercise after acclimatization to 4,300 m. J Appl Physiol. 72 (6): 2435-2445.

[7] Chen SM, Lin HY, Kuo CH (2015). Altitude training improves glycemic control. Chin J Physiol. 56 (4): 193-8.

[8] Conlee RK, Rennie MJ, Winder WW (1976). Skeletal muscle glycogen content: diurnal variation and effects of fasting. Am J Physiol. Aug; 231 (2): 614-18.

[9] Desjardins P, and Conklin D (2010). NanoDrop microvolume quantitation of nucleic acids. J Vis Exp. 22 (45): 2565.

[10] Ge RL, Simonson TS, Gordeuk V, Prchal JT, and McClain DA (2015). Metabolic aspects of high-altitude adaptation in Tibetans. Exp Physiol. 100 (11): 1247-1255.

[11] Gilbert-Kawai ET, Milledge JS, Grocott MP, and Martin DS (2014). King of the mountains: Tibetan and Sherpa physiological adaptations for life at high altitude. Physiology (Bethesda). 29 (6): 388-402.

[12] Hill NE, Deighton K, Matu J, Misra S, Oliver NS, Newman C, Mellor A, O'Hara J, Woods D (2018). Continuous Glucose Monitoring at High Altitude-Effects on Glucose Homeostasis. Med Sci Sports Exerc. Aug; 50 (8): 1679-1686.

[13] Horscroft JA, Kotwica AO, Laner V, West JA, Hennis PJ, Levett DZH, Howard DJ, Fernandez BO, Burgess SL, Ament Z, Gilbert-Kawai ET, Vercueil A, Landis BD, Mitchell K, Mythen MG, Branco C, Johnson RS, Feelisch M, Montgomery HE, Griffin JL, Grocott MPW, Gnaiger E, Martin DS, Murray AJ (2017). Metabolic basis to Sherpa altitude adaptation. Proc Natl Acad Sci U S A. Jun 13; 114 (24): 6382-6387. 
[14] Iyriboz Y, Powers S, Morrow J, Ayers D, and Landry G (1991). Accuracy of pulse oximeters in estimating heart rate at rest and during exercise. Br J Sports Med. 25 (3): 162-164.

[15] Khani S, Tayek JA (2001). Cortisol increases gluconeogenesis in humans: its role in the metabolic syndrome. Clin Sci (Lond). Dec; 101 (6): 739-47.

[16] Kelly KR, Williamson DL, Fealy CE, Kriz DA, Krishnan RK, Huang H, Ahn J, Loomis JL, and Kirwan JP (2010). Acute altitude-induced hypoxia suppresses plasma glucose and leptin in healthy humans. Metabolism. 59 (2): 200-205.

[17] Koufakis T, Karras SN, Mustafa OG, Zebekakis P, Kotsa K (2019). The Effects of High Altitude on Glucose Homeostasis, Metabolic Control, and Other Diabetes-Related Parameters: From Animal Studies to Real Life. High Alt Med Biol. Mar; 20 (1): 1-11.

[18] Lipsitz LA, Hashimoto F, Lubowsky LP, Mietus J, Moody GB, Appenzeller O, and Goldberger AL (1995). Heart rate and respiratory rhythm dynamics on ascent to high altitude. $\mathrm{Br}$ Heart J. 74 (4): 390-396.

[19] Litch JA (1996). Drug-induced hypoglycemia presenting as acute mountain sickness, after mistaking acetohexamide for acetazolamide. Wilderness Environ Med. 7 (3): 232-5.

[20] North KN, Yang N, Wattanasirichaigoon D, Mills M, Easteal S, and Beggs AH (1999). A common nonsense mutation results in alpha-actinin-3 deficiency in the general population. Nat Genet. 21 (4): 353-354.
[21] Quinlan KG, Seto JT, Turner N, Vandebrouck A, Floetenmeyer M, Macarthur DG, Raftery JM, Lek M, Yang N, Parton RG, Cooney GJ, North KN (2010). Alpha-actinin-3 deficiency results in reduced glycogen phosphorylase activity and altered calcium handling in skeletal muscle. Hum Mol Genet. Apr 1; 19 (7): 1335-46.

[22] Roach RC, Maes D, Sandoval D, Robergs RA, Icenogle M, Hinghofer-Szalkay H, Lium D, Loeppky JA (2000). Exercise exacerbates acute mountain sickness at simulated high altitude. J Appl Physiol. 88 (2): 581-5.

[23] Roach RC, Hackett PH, Oelz O, Bärtsch P, Lucks AM, MacInnis MJ, Bailie JK, and The Lake Louise AMS Score Consensus Committee (2018). The 2018 Lake Louise Acute Mountain Sickness Score. High Alt Med Biol. 19 (1): 4-6.

[24] Schadock I, Schneider A, Silva ED, Buchweitz MR, Correa MN, Pesquero JB, Paredes-Gamero EJ, Araujo RC, Barros CC (2015). Simple Method to Genotype the ACTN3 r577x Polymorphism. Genet Test Mel Biomarkers. 19 (5): 253-257.

[25] Vincent B, De Bock K, Ramaekers M, den Eede EV, Van Leemputte M, Hespel P, and Thomis MA (2007). ACTN3 (R577X) genotype is associated with fiber type distribution. Physiol Genomics. 32: 58-63.

[26] Woods DR, Davison A, Stacey M, Smith C, Hooper T, Neely D, Turner S, Peaston R, Mellor A (2012). The cortisol response to hypobaric hypoxia at rest and post-exercise. Horm Metab Res. Apr; 44 (4): 302-5. 